\title{
Avaliação do efeito curativo e preventivo do óleo essencial do capim citronela no controle de Pyricularia grisea
}

\author{
Vilma Borges de Moura Perini ${ }^{1}$, Henrique Guilhon de Castro ${ }^{1^{*}}$, Gil Rodrigues dos Santos ${ }^{1}$, \\ Raimundo Wagner de Souza Aguiar ${ }^{1}$, Evelynne Urzêdo Leão ${ }^{1}$ e Paula Tatiana Lopes \\ Seixas $^{1}$
}

Departamento de Agronomia; Universidade Federal do Tocantins; 77402-970; Gurupi - TO - Brasil.

\begin{abstract}
The rice blast is the most important disease of the rice, due to the damage that it causes in the productivity and grain quality. Aiming at the use of essential oils and plant extracts to control this disease. The objective of this study was to evaluate the curative and preventive effect of the extracts and essential oil of citronella grass (Cymbopogon nardus L.) to control rice blast. The evaluation of the curative effect was performed seven days after the spraying with the extracts of citronella grass. As for the evaluation of preventive effect, the plants were sprayed with the treatments and 24 hours after inoculated with $20 \mathrm{~mL}$ of the spore solution per tray. In the assessing of the curative effect, it was found that the application of fungicide and the diluted essential oil of citronella grass at a concentration of $2 \%$ plants showed no symptoms of blast in 50\% of the repetitions. Regarding the evaluation of preventive effect, the plants showed no symptoms of the disease in concentrations of 1.5, 1.75 and $2 \%$ of the essential oil of citronella grass in $50 \%$ of the repetitions.
\end{abstract}

Key words: Cymbopogon nardus, medicinal plants, fungitoxicity

\section{INTRODUÇÃO}

A brusone, agente causal Pyricularia grisea, é a doença de maior importância da cultura do arroz, devido aos prejuízos que causa na produtividade e na qualidade dos grãos (Santos et al., 2005). Apesar dos esforços de programas de melhoramento genético, a ocorrência de quebra de resistência de novas cultivares desenvolvidas no Brasil tem sido registrada logo após o lançamento devido existir uma grande variabilidade do patógeno (Dias Neto et al., 2010). Desta forma, todas as cultivares plantadas ainda são suscetíveis, em maior ou menor grau, e os fungicidas utilizados na parte aérea não controlam essas doenças de forma eficaz, o que contribui para o encarecimento da produção (Santos et al., 2003). Assim, além dos métodos de controle tradicionais atualmente empregados deve-se buscar técnicas alternativas que possibilitem o manejo sustentável da doença.

As pesquisas de controle de doenças fúngicas por meio do emprego de óleos e extratos vegetais têm crescido consideravelmente nos últimos anos
(Diniz et al., 2008). Marques et al. (2004), relata que a utilização de fungicidas de origem vegetal poderá constituir um método alternativo e promissor no controle de pragas e doenças, pois além de serem de fácil obtenção e baixo custo, minimizam os problemas de toxicidade apresentados pelos produtos químicos sintéticos.

Dentre as plantas medicinais e aromáticas amplamente utilizadas, encontra-se o capim citronela (Cymbopogon nardus L.), cujo óleo essencial possui alto teor de geraniol e citronelal. O citronelal é utilizado como material básico para a síntese de importantes compostos químicos denominados iononas e para a síntese de vitamina A. Esse óleo apresenta atividade repelente a insetos (Wong, 2005; Trongtokit, 2005), e também ação fungicida (Billerbeck et al., 2001; Medice, 2007) e bactericida.

Embora a maioria dos estudos tenha sido realizada com extratos ou óleos essenciais, outros métodos de extração ou produtos podem ser utilizados, como o hidrolato, sendo este o líquido resultante do processo de extração de óleo essencial por

Author for correspondence: hguilhon@uft.edu.br

J. Biotec. Biodivers. v. 2, N.2: pp. 23-27, May. 2011 
arraste a vapor, o qual apresenta geralmente compostos voláteis hidrossolúveis (Lavabre, 1993) e possui grande quantidade de princípios ativos como ácidos aldeídos e aminas.

Desta forma, objetivou-se com este trabalho avaliar o efeito curativo e preventivo de extratos e óleo essencial do capim citronela (Cymbopogon nardus L.) no controle da brusone do arroz.

\section{MATERIAL E MÉTODOS}

Os experimentos foram conduzidos no Laboratório de Fitopatologia e em casa de vegetação na Universidade Federal do Tocantins, Campus de Gurupi.

Utilizou-se a cultivar de arroz Metica 1 para a avaliação do efeito curativo e preventivo de extrato e óleo essencial do capim citronela no controle da brusone do arroz. As sementes foram semeadas em bandejas plásticas $(38 \times 28 \times 7 \mathrm{~cm})$, com 3,5 litros de substrato comercial PLANTMAX $^{\circledR}$ (autoclavados a $120^{\circ} \mathrm{C}$ por $20 \mathrm{~min}$ ), por bandeja.

A multiplicação do inóculo de $P$. grisea foi realizada em placa de Petri contendo meio BDA e incubada por 10 dias.

Aos 25 dias após o plantio foi realizado a inoculação do patógeno nas plantas, na concentração de $3 \times 10^{5}$ conídios $/ \mathrm{mL}$, sendo pulverizado $20 \mathrm{~mL}$ da solução de esporos por bandeja com auxilio de um borrifador manual.

Imediatamente, após a inoculação do patógeno nas plantas as bandejas foram mantidas em câmara úmida com umidade relativa maior que $95 \%$ com ausência total de luz, por 24 horas. Para favorecer o desenvolvimento das lesões, as bandejas foram levadas para a câmara de crescimento sob temperatura de $25^{\circ} \mathrm{C}$ e $70 \%$ de umidade relativa por sete dias.

A avaliação foi feita por meio da análise visual das lesões nas plantas (com sintoma - CS e sem sintoma - SS), realizada sete dias após a inoculação do patógeno.

Ensaio I - Avaliação do efeito curativo de extratos e óleo essencial do capim citronela no controle da brusone.

Para a verificação do efeito curativo de extratos e óleo essencial do capim citronela no controle da brusone foi instalado um experimento com dez tratamentos e oito repetições. Cada repetição foi constituída por uma linha com doze plantas. Verificado a presença de lesões após a inoculação do patógeno, as plantas foram pulverizadas com os tratamentos (20 mL por bandeja) e após sete dias da pulverização foi realizada a avaliação das reações.

Os tratamentos empregados foram: $\mathrm{T} 1=20 \mathrm{~mL}$ de água - Testemunha; $\mathrm{T} 2=20 \mathrm{~mL}$ de água $+300 \mu \mathrm{L}$ de Tween; $\mathrm{T} 3=20 \mathrm{~mL}$ de hidrolato; $\mathrm{T} 4=20 \mathrm{~mL}$ de água $+0,4 \mu \mathrm{L}$ de fungicida (Tiofanato metílico); $\mathrm{T} 5=20 \mathrm{~mL}$ de água $+300 \mu \mathrm{L}$ de Tween $+0,4 \mathrm{~mL}$ de óleo essencial diluído; T6 $=20 \mathrm{~mL}$ de água + $300 \mu \mathrm{L}$ de Tween $+0,8 \mathrm{~mL}$ de óleo essencial diluído; $\mathrm{T} 7=20 \mathrm{~mL}$ de água $+300 \mu \mathrm{L}$ de Tween + $1,2 \mathrm{~mL}$ de óleo essencial diluído; $\mathrm{T} 8=20 \mathrm{~mL}$ de água $+300 \mu \mathrm{L}$ de Tween $+1,6 \mathrm{~mL}$ de óleo essencial diluído; $\mathrm{T} 9=20 \mathrm{~mL}$ da solução de maceração; T10 $=20 \mathrm{~mL}$ da solução de infusão.

\section{Ensaio II - Avaliação do efeito preventivo do} óleo essencial do capim citronela no controle da brusone.

Para a verificação do efeito preventivo do óleo essencial do capim citronela no controle da brusone, foi instalado um experimento com nove tratamentos e seis repetições. As plantas foram pulverizadas com os tratamentos $(20 \mathrm{~mL})$ e após 24 horas foram inoculadas com $20 \mathrm{~mL}$ da solução de esporos por bandeja. A concentração da solução de esporos foi ajustada para $3 \times 10^{5}$ conídios $/ \mathrm{mL}$. Os tratamentos utilizados foram: $\mathrm{T} 1=20 \mathrm{~mL}$ de água - Testemunha; $\mathrm{T} 2=20 \mathrm{~mL}$ de água $+300 \mu \mathrm{L}$ de Tween $+50 \mu \mathrm{L}$ do óleo essencial diluído; T3= $20 \mathrm{~mL}$ de água $+300 \mu \mathrm{L}$ de Tween $+100 \mu \mathrm{L}$ do óleo essencial diluído; $\mathrm{T} 4=20 \mathrm{~mL}$ de água +300 $\mu \mathrm{L}$ de Tween $+150 \mu \mathrm{L}$ do óleo essencial diluído; $\mathrm{T} 5=20 \mathrm{~mL}$ de água $+300 \mu \mathrm{L}$ de Tween $+200 \mu \mathrm{L}$ do óleo essencial diluído; $\mathrm{T} 6=20 \mathrm{~mL}$ de água + $300 \mu \mathrm{L}$ de Tween $+250 \mu \mathrm{L}$ do óleo essencial diluído; $\mathrm{T} 7=20 \mathrm{~mL}$ de água $+300 \mu \mathrm{L}$ de Tween + $300 \mu \mathrm{L}$ do óleo essencial diluído; $\mathrm{T} 8=20 \mathrm{~mL}$ de água $+300 \mu \mathrm{L}$ de Tween $+350 \mu \mathrm{L}$ do óleo essencial diluído; $\mathrm{T} 9=20 \mathrm{~mL}$ de água $+300 \mu \mathrm{L}$ de Tween $+400 \mu \mathrm{L}$ do óleo essencial diluído.

\section{RESULTADOS E DISCUSSÃO}

Ensaio I - Avaliação do efeito curativo de extratos e óleo essencial do capim citronela no controle da brusone.

Em relação à aplicação do tween, maceração e infusão, a reação das plantas, em todas as repetições, foi suscetível (Tabela 1).

Quanto à aplicação do hidrolato, verificou-se que em duas repetições, a reação das plantas foi 
considerada resistente e nas outras seis repetições a reação foi suscetível. Franzener et al. (2007) avaliando a atividade antifúngica, antibacteriana e indutora da produção de fitoalexinas dos hidrolatos de Helietta apiculata (canela-de-veado), Conyza canadensis (buva) e Cymbopogon nardus (citronela) observaram que, independentemente da concentração utilizada, não se observou alteração sensível no crescimento micelial de Alternaria brassicae, demonstrando que há a presença dos compostos, porém em baixas concentrações.

Em relação à aplicação do fungicida e do óleo essencial diluído do capim citronela na concentração de $2 \%$, verificou-se que em quatro repetições, as plantas não apresentaram sintomas da doença (Tabela 1). Estes resultados mostraram o potencial do uso do óleo essencial do capim citronela no controle da brusone no arroz. Wilson et al. (1997), utilizando extrato bruto de $C$. nardus, não obtiveram efeito antimicrobiano sobre Botrytis cinerea, No entanto, em concentração de $6,25 \%$ do óleo essencial, observaram o efeito fungitóxico sobre a germinação de esporos de $B$. cinerea, demonstrando que os compostos antifúngicos sintetizados por $C$. nardus possam se concentrar no óleo essencial e estarem presentes em concentrações muito baixas no hidrolato.

Entretanto, Lima (2007), verificou que, para fins curativos, o óleo de citronela tem efeito limitado na concentração de 2000 ppm quanto ao índice de doença final (IDF). Isso pode ser devido a não atuação do óleo sobre as estruturas fúngicas quando no interior do tecido vegetal, colaborando para elevação do IDF.

Verificou-se após 15 minutos da aplicação do óleo essencial diluído do capim citronela, nas concentrações de 4, 6 e 8\%, que as plantas começaram a secar. Após 24 horas da aplicação, foi observado que as plantas apresentavam suas folhas totalmente desidratadas. Portanto, não foi possível realizar a avaliação das plantas nesses tratamentos. Esses resultados mostram o potencial fitotóxico do óleo essencial do capim citronela em plantas de arroz.

Tabela 1. Resultados da avaliação do efeito curativo das plantas tratadas com diferentes tipos de extratos e concentrações do óleo essencial diluído do capim citronela no controle da brusone do arroz. Gurupi. UFT, 2010.

\begin{tabular}{cllllllll}
\hline \multirow{2}{*}{ Tratamentos } & \multicolumn{8}{c}{ Repetições } \\
\cline { 2 - 8 } & R1 & R2 & R3 & R4 & R5 & R6 & R7 & R8 \\
\hline Água & CS & CS & CS & CS & CS & CS & CS & CS \\
Tween & CS & CS & CS & CS & CS & CS & CS & CS \\
Hidrolato & SS & CS & SS & CS & CS & CS & CS & CS \\
Maceração & CS & CS & CS & CS & CS & CS & CS & CS \\
Infusão & CS & CS & CS & CS & CS & CS & CS & CS \\
Fungicida & SS & CS & SS & CS & SS & CS & SS & CS \\
Óleo (2\%) & SS & CS & SS & CS & CS & SS & CS & SS \\
\hline
\end{tabular}

$\mathrm{CS}$ - planta com sintomas da brusone; $\mathrm{SS}$ - plantas sem sintomas da brusone.

Ensaio II - Avaliação do efeito preventivo do óleo essencial do capim citronela no controle da brusone.

Verificou-se que com a utilização das concentrações $0 ; 0,25 ; 0,50$ e $0,75 \%$ do óleo essencial diluído do capim citronela, as plantas apresentaram sintomas da brusone em todas as repetições. Entretanto, com a utilização do óleo essencial diluído do capim citronela nas concentrações de 1 e $1,25 \%$, as plantas não apresentaram sintomas da brusone em duas repetições (Tabela 2).

Em relação às concentrações de 1,5; 1,75 e 2\% do óleo essencial diluído do capim citronela foram observados que as plantas não apresentaram sintomas em três repetições (Tabela 2).

Lima (2007), ao analisar a área abaixo da curva de progresso da doença (AACPD), índice de doença final (IDF), período de incubação (PI) e taxa de progresso da doença (TPD), observou que os tratamentos preventivos do óleo de citronela e fungicida diferiram significativamente da testemunha, verificando assim, que o óleo de citronela apresentou efeito preventivo da ramulose do algodoeiro sob condições de casa-de-vegetação. O óleo essencial do $C$. nardus possui efeito fungicida e fitotóxico. Entretanto, outros estudos devem ser realizados para verificar quais são os 
potencial para uso como insumo agrícola.

Tabela 2. Resultados da avaliação do efeito preventivo de diferentes concentrações do óleo essencial diluído do capim citronela em plantas de arroz. Gurupi. UFT, 2010.

\begin{tabular}{ccccccc}
\hline \multirow{2}{*}{ Concentrações $(\boldsymbol{\%})$} & \multicolumn{7}{c}{ Repetições } \\
\cline { 2 - 7 } & R1 & R2 & R3 & R4 & R5 & R6 \\
\hline 0,00 & CS & CS & CS & CS & CS & CS \\
0,25 & CS & CS & CS & CS & CS & CS \\
0,50 & CS & CS & CS & CS & CS & CS \\
0,75 & CS & CS & CS & CS & CS & CS \\
1,0 & SS & CS & CS & CS & SS & CS \\
1,25 & CS & CS & SS & CS & CS & SS \\
1,50 & CS & SS & CS & SS & SS & CS \\
1,75 & SS & SS & CS & SS & CS & CS \\
2,0 & SS & CS & SS & CS & CS & SS \\
\hline
\end{tabular}

$\mathrm{CS}$ - planta com sintomas da brusone; $\mathrm{SS}$ - plantas sem sintomas da brusone.

\section{AGRADECIMENTOS}

O presente trabalho foi realizado com o apoio do Conselho Nacional de Desenvolvimento Científico e Tecnológico.

\section{RESUMO}

A brusone é a doença de maior importância da cultura do arroz, devido aos prejuízos que causa na produtividade e na qualidade dos grãos. Visando o emprego de óleos essencial e extratos vegetais no controle desta doença, objetivou-se com este trabalho avaliar o efeito curativo e preventivo de extratos e óleo essencial do capim citronela (Cymbopogon nardus L.) no controle da brusone do arroz. A avaliação do efeito curativo foi realizada após sete dias da pulverização com os extratos do capim citronela. Quanto à avaliação do efeito preventivo, as plantas foram pulverizadas com os tratamentos e após 24 horas inoculadas com $20 \mathrm{~mL}$ da solução de esporos por bandeja. $\mathrm{Na}$ avaliação do efeito curativo, verificou-se que com a aplicação do fungicida e do óleo essencial diluído do capim citronela na concentração de $2 \%$ as plantas não apresentaram sintomas da brusone em 50\% das repetições. Em relação à avaliação do efeito preventivo, as plantas não apresentaram sintomas da doença nas concentrações de 1,$5 ; 1,75$ e $2 \%$ do óleo essencial do capim citronela em $50 \%$ das repetições.

Palavras-chave: Cymbopogon nardus, plantas medicinais, fungitoxicidade

\section{REFERÊNCIAS}

Billerbeck, V. G.; Roques C. G.; Bessière, J. M.; Fonvieille, J.L.; Dargent, R. (2001), Effects of Cymbopogon nardus (L.) W. Watson essential oil on the growth and morphogenesis of Aspergillus niger. Canadian Journal of Microbiology. 47, 917.
Dias Neto, J. J.; Santos, G. R.; Anjos, L. M.; Rangel, P.H.N. (2010), Hot spots for diversity of Magnaporthe oryzae physiological races in irrigated rice fields in Brazil. Pesquisa Agropecuária Brasileira, 45, 252-260.

Diniz, S. P. S. S.; Coelho, J. S.; Rosa, G. S.; Specian, V.; Oliveira, R. C.; Oliveira, R. R. (2008), Bioatividade do óleo essencial de Mentha arvensis L. no controle de fungos fitopatógenos.. Revista Brasileira de Plantas Medicinais, 10, 911.

Franzener, G.; Martinez-Franzener, A. S.; Stangarlin, J. R.; Czepak, M. P.; Schwan-Estrada, K. R. F.; Cruz, M. E. S. (2007), Atividades antibacteriana, antifúngica e indutora de fitoalexinas de hidrolatos de plantas medicinais. Semina: Ciências Agrárias, 28, 29-38.

Lavabre, M. (1993), Aromaterapia: a cura pelos óleos essenciais. $5^{\text {a }}$ Ed. Rio de Janeiro: Nova Era. 172p.

Lima, W. G. Controle alternativo da ramulose do algodoeiro via utilização de óleos essenciais. Dissertação (Mestrado) - Universidade Federal Rural de Pernambuco, 2007.

Marques, R. P.; Monteiro, A. C.; Pereira, G. T. (2004), Crescimento, esporulação e viabilidade de fungos entomopatogenicos em meios contendo diferentes concentrações do óleo de nim (Azadirachta indica). Ciência Rural, 34, 16751680. 
Medice, R.; Alves, E.; Assis, R. T.; Magno Júnior, R.G.; Lopes, E. A. G. L. (2007), Óleos essenciais no controle da ferrugem asiática da soja Phakopsora pachyrhizi Syd. \& P. Syd. Ciência Agrotécnica. 31, 83-90.

Santos, G. R.; Korndorffer, G.; Reisilho, J. C. D.; Pelúzio, J. M. (2003), Adubação com silício: influência sobre as principais doenças e sobre rodutividade de arroz irrigado por inundação. Revista Ceres, 50, 1-8.

Santos, G. R.; Rangel, P. H. N.; Santiago, C. M.; Leão, F. F.; Marra, B.; Almeida J. D. (2005), Reação a doenças e caracteres agronômicos de genótipos de arroz de várzeas no Estado do Tocantins. Revista Agropecuária Técnica, 26, 51 57.
Trongtokit, Y.; Rongsrivam, Y.; Komalamisra, N.; Apiwathnasom, C. (2005), Comparative repellency of 38 essential oils against mosquito bites. Phytotherapy Research, 19, 303-309.

Wilson, C. L.; Solar, J. M.; El Ghaouth, A.; Wisniewski, M. E. (1997), Rapid evaluation of plant extracts and essential oils for antifungal activity against Botrytis cinerea. Plant Disease, 81, 204-210.

Wong, K. K; Signal, F. A.; Campion, S. H.; Motion, R. L. (2005), Citronella as an insect repellent in food packaging. Journal of Agricultural and Food Chemistry, 53, 4633- 4636. 